\title{
Methemoglobinemia during the Use of Glyceryl Trinitrate Patches in Neonates: Two Case Reports
}

\author{
Alison Mintoft, MRCPCH ${ }^{1}$ Emma Williams, MRCPCH ${ }^{2}$ Christopher Harris, MRCPCH $\mathrm{M}^{3,4}$ \\ Nigel Kennea, $\mathrm{PhD}^{5}$ Anne Greenough, MD(Cantab) $3,4,6$
}

${ }^{1}$ Neonatal Intensive Care Centre, Evelina Children's Hospital, Guy's and St Thomas' NHS Foundation Trust, London, United Kingdom

2 Neonatal Intensive Care Centre, King's College Hospital NHS Foundation Trust, London, United Kingdom

${ }^{3}$ MRC \& Asthma UK Centre in Allergic Mechanisms of Asthma, King's College London, London, United Kingdom

4 Department of Women and Children's Health, School of Life Course Sciences, Faculty of Life Sciences and Medicine, King's College London, London, United Kingdom

${ }^{5}$ Neonatal Intensive Care Centre, St George's Hospital NHS

Foundation Trust, London, United Kingdom

${ }^{6}$ NIHR Biomedical Research Centre at Guy's and St Thomas' NHS

Foundation Trust and King's College London, London, United Kingdom

\author{
Address for correspondence Anne Greenough, MD(Cantab), \\ Neonatal Intensive Care Unit, King's College Hospital, 4th Floor \\ Golden Jubilee Wing, Denmark Hill, London SE5 9RS, United Kingdom \\ (e-mail: Anne.greenough@kcl.ac.uk).
}

Am J Perinatol Rep 2018;8:e227-e229.

\begin{abstract}
Keywords

- methemoglobinemia

- preterm

- glyceryl trinitrate

- ischemia

Methemoglobinemia can result in severe hypoxia. It has been frequently reported during the use of inhaled nitric oxide, but can occur where nitrate containing medications are used. Glyceryl trinitrate (GTN) patches have been used in the treatment of digital and limb ischemia in prematurely born infants. Little is known about the pharmacokinetics of GTN when incorporated into patches. Studies of other topical forms of nitroglycerine have shown a wide range of absorption. It is likely that the increased permeability of the prematurely born infant's skin would facilitate absorption. We describe the use of GTN patches in two very prematurely born infants used to treat limb/digit ischemia. This resulted in methemoglobinemia and resultant increase in their supplementary oxygen requirements. Removal of the patches was associated with a reduction in their methemoglobin levels and the supplementary oxygen requirements back to baseline levels. In conclusion, routine monitoring of methemoglobin levels should be undertaken when GTN patches are used in very prematurely born infants.
\end{abstract}

Methemoglobinemia is formed as a result of the oxidization of iron from its ferrous $\left(\mathrm{Fe}^{2+}\right)$ to ferric $\left(\mathrm{Fe}^{3+}\right)$ state and can occur following exposure not only to inhaled nitric oxide (iNO) but also nitrite containing medications. Methemoglobinemia has been frequently reported in infants treated with iNO. ${ }^{1}$ The levels of methemoglobinemia relate to the iNO levels used. ${ }^{1}$ Methemoglobin has a higher oxygen-binding capacity than hemoglobin and thus affected infants can suffer severe hypoxia. Ischemia can be caused by a combination of vascular damage and concomitant vasoconstriction. ${ }^{2}$ Glyceryl trinitrate (GTN) patches are used in the treatment of ischemic digits and limbs in neonates ${ }^{2,3}$ and in adults. ${ }^{4}$ GTN is converted to NO in the vascular smooth muscle, and this activates guanylate cyclase and increases the levels of cyclic guanosine monophosphate (cGMP); ${ }^{5}$ cGMP causes relaxation of the vascular smooth muscle in the affected artery and received

March 28, 2018 accepted after revision July 26, 2018
DOI https://doi.org/

10.1055/s-0038-1669945. ISSN 2157-6998.
Copyright $\odot 2018$ by Thieme Medical Publishers, Inc., 333 Seventh Avenue, New York, NY 10001, USA. Tel: +1(212) 584-4662.
License terms

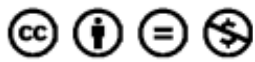


dilation of the collateral circulation. ${ }^{2}$ GTN patches, however, remain unlicensed for use in neonates and little is known about the pharmacokinetics of GTN when used in patch formation in prematurely born neonates. Methemoglobinemia is not listed as a side effect of the use of GTN patches. The absorption of nitroglycerin from topical ointments has been shown to be variable in infants. GTN patches vary in size and dose. A $10-\mathrm{cm}^{2}$ patch typically contains $40 \mathrm{mg}$ of nitroglycerin and is designed to release this at $0.2 \mathrm{mg} / \mathrm{h}$; however, in one study of seven infants, an application of $1 \mathrm{mg}$ in an ointment resulted in blood levels of between 0.03 and 3.36 $\mathrm{ng} / \mathrm{mL} .{ }^{6}$ The skin of prematurely born infants has increased permeability compared with term born infants which might lead to greater absorption of topical treatments. ${ }^{7}$ We present two cases of methemoglobinemia which occurred during the use of GTN patches to treat ischemic digits and limbs of very prematurely born infants. In both cases, $9 \mathrm{~cm}^{2}$ patches were used which contained $18.7 \mathrm{mg}$ GTN.

\section{Case 1}

An infant with a birth weight of $650 \mathrm{~g}$ was born at 24 weeks of gestational age following the onset of spontaneous preterm labor. During initial resuscitation, it was noted that the lower limbs of the infant were dusky and this did not resolve despite improving the blood pressure levels by administering volume replacement and inotropes. One GTN patch was applied to each lower limb over the area of the posterior tibial arteries. These were left in place as the infant was stabilized and transferred to the local tertiary unit. A radial arterial line was inserted the following day, day 2 after birth. The thumb and forefinger distal to the radial arterial line became poorly perfused shortly after insertion and a further GTN patch was applied to the hand. This was in addition to the two patches in situ on the feet. The oxygen requirement was noted to rise from an inspired oxygen fraction $\left(\mathrm{FiO}_{2}\right)$ of 0.21 to 0.4 within 6 hours of application of the third patch. The infant's inspired oxygen concentration was altered as necessary to keep the oxygen saturation levels between 92 and 95\%. Serial capillary blood gases showed an increase in methemoglobinemia from $1.1 \%$ prearterial line insertion to $8.4 \%$ over 6 hours. In total, three patches had been applied over the 48 -hour period. All patches were immediately removed and the methemoglobinemia level fell to less than $1 \%$ within 2 hours. There was a corresponding reduction in the oxygen requirement to the level prior to the application of the patch. Perfusion of the hand and lower limbs completely recovered.

\section{Case 2}

An infant with a birth weight of $617 \mathrm{~g}$ was born at 24 weeks of gestational age via a vaginal delivery following premature rupture of membranes 1 week previously. After initial resuscitation, the infant was transferred to a tertiary neonatal unit. Umbilical arterial access was not obtained and a right posterior tibial arterial line was inserted on day 2 after birth. The following day, it was noted that it was difficult to sample from the arterial line and to obtain an adequate blood pressure trace. The toes and foot were cool to touch and blanched white on examination. The arterial line was removed and a GTN patch immediately applied and replaced daily. The toes on the right foot became necrotic on day 7 and, following consultation with the vascular team, two GTN patches were applied to the foot, one proximally and one posteriorly to the point where the arterial line had been inserted. The patches were changed twice daily. Over the following 24 hours, the infant's supplementary oxygen requirement increased from an $\mathrm{FiO}_{2}$ of 0.23 to an $\mathrm{FiO}_{2}$ of 0.70 . The infant's inspired oxygen concentration was altered as necessary to keep the oxygen saturation levels between 92 and $95 \%$. At that time, it was noted that the methemoglobin level was $14.5 \%$. The GTN patches were immediately removed. A total of 10 patches had been used during the previous 5 days and 5 of those patches had been sited in 24 hours prior to removal of the patches. Over the following 24 hours, the methemoglobin level fell from the highest level of 23.3 to $2.5 \%$, with a corresponding reduction in the oxygenation index (mean airway pressure $\times \mathrm{FiO}_{2} \times 100$ divided by $\mathrm{PaO}_{2}, \mathrm{kPa}$ ), from 24 to 8 . The tips of the toes that were necrotic sloughed off after several weeks, but no amputation was required.

\section{Discussion}

We have demonstrated GTN patch use in very prematurely born infants can result in methemoglobinemia. In both infants, this was associated with an increase in their inspired oxygen requirement. In the first case, the ischemia completely resolved, but in the second resolution was incomplete and as a consequence, the toes became necrotic. In both cases due to the development of the methemoglobinemia, the patches were removed prematurely, which may have reduced their efficacy. Previous case reports have suggested a treatment duration of 28 days. $^{2}$

It is not clear whether the methemoglobinemia was the cumulative effect of all the patches applied or after a certain number of patches a threshold was reached. It is known, however, that prematurely born infants have lower levels of methemoglobin reductase which makes them more susceptible to methemoglobinemia. ${ }^{8,9}$ Once the patches were removed, the methemoglobin levels decreased and the supplementary oxygen requirement returned to the level prior to treatment with the patches. Thus, we suggest the use of the GTN patches resulted in the methemoglobinemia. As a consequence, we recommend if GTN patches are used in a very prematurely born infant, frequent assessment of methemoglobin levels should be undertaken.

Conflict of Interest

None.

\section{References}

1 Hamon I, Gauthier-Moulinier H, Grelet-Dessioux E, Storme L, Fresson J, Hascoet JM. Methaemoglobinaemia risk factors with inhaled nitric oxide therapy in newborn infants. Acta Paediatr 2010;99(10):1467-1473 
2 Vasquez P, Burd A, Mehta R, Hiatt M, Hegyi T. Resolution of peripheral artery catheter-induced ischemic injury following prolonged treatment with topical nitroglycerin ointment in a newborn: a case report. J Perinatol 2003;23(04):348-350

3 Varughese M, Koh TH. Successful use of topical nitroglycerine in ischaemia associated with umbilical arterial line in a neonate. J Perinatol 2001;21(08):556-558

4 Boyce L, Dhukaram V. Transdermal glyceryl trinitrate in the treatment of ischemia following toe deformity correction: a case series. Foot Ankle Int 2014;35(11):1226-1230

5 Ignarro LJ, Cirino G, Casini A, Napoli C. Nitric oxide as a signaling molecule in the vascular system: an overview. J Cardiovasc Pharmacol 1999;34(06):879-886
6 Guran P, Beal G, Brion N, Advenier C. Topical nitroglycerin as an aid to insertion of peripheral venous catheters in neonates. J Pediatr 1989;115(06):1025

7 Pinsker JE, McBayne K, Edwards M, Jensen K, Crudo DF, Bauer AJ. Transient hypothyroidism in premature infants after short-term topical iodine exposure: an avoidable risk? Pediatr Neonatol 2013;54(02):128-131

8 Kravitz H, Elegant LD, Kaiser E, Kagan BM. Methemoglobin values in premature and mature infants and children. AMA J Dis Child 1956;91(01):1-5

9 Haymond S, Cariappa R, Eby CS, Scott MG. Laboratory assessment of oxygenation in methemoglobinemia. Clin Chem 2005;51(02): 434-444 